\title{
Constructive conflicts of interest: an alternative perspective from industry?
}

\author{
Marc Wysocki* (i)
}

(0) 2018 Springer-Verlag GmbH Germany, part of Springer Nature

\section{Introduction}

Making transparent the so-called conflicts of interest (COIs) is nowadays a common practice for any scientific publication and lecture. Indeed such declarations are not to prevent COIs, but to warn the audience and the readers that opinions, statements and suggestions might be influenced by the author's or speaker's affiliations.

The paper by Truog and Curtis [1] in the present journal nicely describes what a COI is and all the situations where it may happen. In the scientific community, a common belief is to consider a COI as something "bad" which should be avoided without ambiguity [2]

The present paper would like to try a counterintuitive approach and by better understanding "what's (really) wrong with COIs" finding a middle ground approach where the traditional "dark side" (industry) and the obviously "bright side" (clinicians) would work together to share the "force" (resources) for mutual and synergistic interests in what can be called a "constructive conflict of interest".

\section{What's wrong with COIs?}

Considering that (1) "conflict" is everywhere, between and within individuals, and sometimes has beneficial outputs when such conflicts are constructive; (2) having more than one interest as reported by Turnbull and coworkers [3], and which need to be prioritized during the decision process is very trivial; (3) "influence" is part of human relationships, from childhood where parents are influencers to the adulthood where teachers, colleagues, and leaders are influencing our attitudes and decisions, it finally appears that the problem with COI is not about the "conflict", not about the "interest" and not about

*Correspondence: marc.wysocki@ge.com

GE Healthcare, 283 rue de la Minière, 78533 Buc, France "influence" but more about "how to influence" the decision. Influencing a decision-maker by providing personal and private advantages, including small gifts, and meals is definitely not acceptable. Influencing a decision by supporting research, education and guidelines is also not acceptable $[4,5]$.

The following example may help in understanding what a COI is but also the limits of the above definition:

As an ICU director I have to renew my fleet of ventilators. I can choose among several brands and I have to specify my needs before entering a public tender:

- I want a device with the best performance to provide the best ventilation to my patient (patient interest).

- I want an easy-to-use device to help the team working in the unit (team interest).

- I want a cost-effective device as my budget is limited (organization interest).

- I want a device with research capabilities (my interest).

These needs are creating conflicts in the decision process but nothing is wrong so far. Assuming that there is more than one ventilator covering my needs and to help in making the decision, I may get advice from colleagues inside and outside the organization. I may set up a committee to ensure a democratic discussion before making the decision. I may meet with the vendors to hear what they have to say. I may organize bench testings or literature reviews to know more about the specifications and the usability of such ventilators. All this will "influence" my decision and again nothing is wrong with that. But getting sponsorship from one of those competing companies to support my research will consciously or subconsciously "favour" that company's ventilator through the tender process and this is not acceptable [1-3]. Let's

\section{Springer}


assume, however, that by accepting the sponsorship and being able to do the research, it ends up with positive results changing the practices for the patient's benefit. That was the case with noninvasive ventilation, where the initial investigations on COPD patients $[6,7]$ would have been hardly possible without an industrial partnership. Let's assume also that I'm accepting the sponsorship to make the research possible; and to avoid COI, I decide intentionally to not buy any product from that company; it may end up by not offering the patient a ventilator with potential benefits and this is also arguable.

Besides obvious conflicts of interest where personal and financial interests are driving the decision, there are grey zones which can not be solved by a Manichaean position.

Conflicts of interest are ubiquitous and "influences" (as far as not being driven by personal advantages) are ultimately the way to get an agreement, to resolve the conflict and to find the best solution for the entire system (patient, healthcare workers and organizations).

\section{COI is great!}

It sounds provocative but again, as long as no personal advantage is involved in the decision process, having a conflict with various influences to help one take the best decision for the patient and the organization is maybe desirable.

Interestingly, teamwork and routine multidisciplinary clinical rounds with inherent conflicts have been advocated as an optimal approach to take care of the most critically ill patients $[7,8]$. This has been also advocated in the industrial world as the "creative power of constructive conflict" [9].

In the present context, conflicting interests between industry that is driven by profitability and clinicians who are driven by the patient's welfare do not mean that nothing can be done together or that clear segregation should exist between these two worlds.

By mapping the possible interactions between industry and healthcare professionals (Fig. 1), it appears that such interactions may also result in synergies and opening room for opportunities.

When a conflict happens (divergent interests between healthcare providers and industry) mutual influences may help move both sides to a synergetic model.

Typically, industry may refine the solution or the product to better meet the needs and find synergy with the medical world.

The risk of COIs persists when a competition exists between similar solutions from different industries which, however, can be minimized by strong upstream product definition during the design phase where key

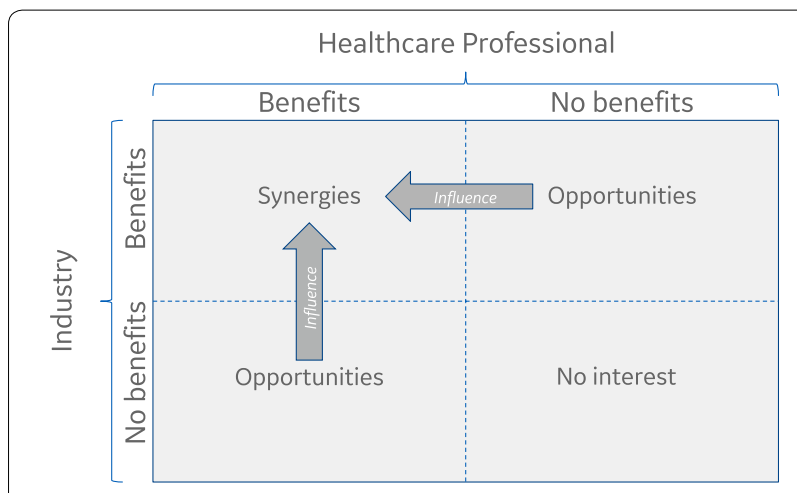

Fig. 1 Perceived benefits of a product or a solution and the possible interactions between industry and healthcare professionals. When both parties perceived a benefit it can generate a product or a solution with synergistic benefits for the patient. When there is a conflict between both parties, influential interactions and refinements should help move the product or the solution toward the synergistic corner

differentiators are critical before moving to the development phase.

\section{COls for consenting adults only}

As conflicting interests are not totally avoidable and indeed are potentially constructive, facing the interactions between industry and healthcare professionals without fear or fantasy is key. Industrial companies are definitely not philanthropic organizations, but nevertheless they have to interact with clinicians to understand the needs, to run clinical investigations for pre-market authorization, post-market evaluation, but also to support their marketing claims. Without interactions with healthcare professionals the risk is to design products or solutions with little value for the patients, resulting in a waste of time and of resources.

On the other side, clinicians may also need to interact with industry and without such interaction the chance of having a "good and nice idea" translated into a tangible product or solution in the market is very low. It might consequently be a waste of resources for the academic organizations and potentially a loss of chances for the patient. Industry may help open up the market for products and solutions being developed locally which otherwise would stay confidential.

In addition, for some specific and complex topics (big data, artificial intelligence), industry or the medical community alone will hardly be able to find or provide a valuable solution for the patient.

\section{Conclusions}

Yes, there is a risk of COIs as far as an interaction exists between industry and the scientific community and everything should be done to avoid influencing the decision process in terms of private, personal or financial advantages. 
Being dogmatic with clear segregation between industry and the scientific community is certainly not realistic or helpful.

In the present paper we advocate for a "constructive" conflict of interest which assumes that a conflict may help in finding a synergistic approach to serve both parties (industry and healthcare professionals) and ultimately the patients and healthcare organizations.

Ostracising industry and not taking advantage of its specific expertise and values is most probably not the right approach. Rigour and compliance with existing regulations should help in considering COIs without fear. In addition, innovative models of interactions like consortiums [10], where goals, respective contributions and retributions, intellectual property, executions, process and budget are clearly defined and transparent, need further evaluation but may help in facing the shortage in public funding and creating constructive and respectful interactions.

\section{Compliance with ethical standards}

\section{Conflicts of interest}

Dr. M. Wysocki is a full-time employee of GE Healthcare.

\section{Publisher's Note}

Springer Nature remains neutral with regard to jurisdictional claims in published maps and institutional affiliations.

Received: 7 August 2018 Accepted: 11 December 2018 Published online: 19 December 2018
References

1. Truog RD, Curtis JR (2018) Conflicts of interest in critical care partnerships: are we living up to our values? Intensive Care Med. https://doi. org/10.1007/s00134-018-5283-9

2. Tobin MJ (2018) Conflicts of interest and the patient-doctor covenant. Intensive Care Med. https://doi.org/10.1007/s00134-018-5282-x

3. Turnbull AE et al (2018) Competing and conflicting interests in the care of critically ill patients. Intensive Care Med. https://doi.org/10.1007/s0013 4-018-5326-2

4. Antonelli M, Coopersmith CM (2018) Professional medical societies: do we have any conflict of interest with industry? Intensive Care Med. https ://doi.org/10.1007/s00134-018-5304-8

5. Brochard L, Isabey D, Piquet J, Amaro P, Mancebo J, Messadi AA, BrunBuisson C, Rauss A, Lemaire F, Harf A (1990) Reversal of acute exacerbations of chronic obstructive lung disease by inspiratory assistance with a face mask. N Engl J Med 323:1523-1530

6. Brochard L, Mancebo J, Wysocki M, Lofaso F, Conti G, Rauss A, Simonneau G, Benito S, Gasparetto A, Lemaire F et al (1995) Noninvasive ventilation for acute exacerbations of chronic obstructive pulmonary disease. N Engl J Med 333:817-822

7. Parker MM (2016) Teamwork in the ICU—do we practice what we preach? Crit Care Med 44:254-255

8. Rhodes A, Moreno RP, Azoulay E, Capuzzo M, Chiche JD, Eddleston J, Endacott R, Ferdinande P, Flaatten H, Guidet B, Kuhlen R, León-Gil C, Martin Delgado MC, Metnitz PG, Soares M, Sprung CL, Timsit JF, Valentin A (2012) Prospectively defined indicators to improve the safety and quality of care for critically ill patients: a report from the Task Force on Safety and Quality of the European Society of Intensive Care Medicine (ESICM). Intensive Care Med 38:598-605

9. Immelt JR (2015) GE annual report. https://www.ge.com/ar2015/letter. Accessed 7 Aug 2018

10. https://www.combacte.com. Accessed 17 Sept 2018 